\title{
Effect of Delignification on Hemicellulose Extraction from Switchgrass, Poplar, and Pine and Its Effect on Enzymatic Convertibility of Cellulose-rich Residues
}

\author{
Wenhui Geng, Richard A. Venditti,* Joel J. Pawlak, and Hou-min Chang \\ Hemicellulose is an abundant and underutilized carbohydrate polymer in plants. \\ The objective of this study was to understand the effect of delignification on \\ hemicellulose extraction efficiency with different types of lignocellulosic biomass. \\ In the case of pine, with a prior sodium chlorite or peracetic acid delignification, \\ more than $50 \%$ of the original hemicellulose in the biomass could be extracted \\ using a $10 \%$ sodium hydroxide solution; without delignification, only $3.4 \%$ of \\ hemicellulose could be extracted from pine. In contrast, without prior \\ delignification, acceptable hemicellulose extraction efficiencies $(55.5 \%$ and $50.7 \%$, \\ respectively) were achieved from switchgrass and poplar. In addition, the effect of \\ hemicellulose extraction processes on the enzymatic convertibility of the cellulose- \\ rich residues after extraction was determined. The cellulose-rich residues from \\ switchgrass after hemicellulose alkali extraction showed high glucose recovery \\ with enzyme hydrolysis with or without prior delignification. For pine and poplar, \\ high glucose recovery with enzyme hydrolysis of the cellulose-rich residues only \\ occurred if the sample had a delignification step prior to hemicellulose extraction. \\ This information on commercially available biomass feedstocks is useful for those \\ considering isolating hemicellulose within a biorefinery concept.
}

Keywords: Hemicellulose; Delignification; Alkaline extraction; Enzymatic hydrolysis

Contact information: Department of Forest Biomaterials, North Carolina State University, P. O. Box 8005, Raleigh, NC 27695-8005, USA; *Corresponding author: richard_venditti@ncsu.edu

\section{INTRODUCTION}

Lignocellulosic biomass has great potential to serve as a sustainable raw material supply for fuels, chemicals, and biopolymers because of its availability, high sugar content, and low price. Lignocellulosic biomass is comprised of 25 to $55 \%$ cellulose, 25 to $40 \%$ hemicellulose, and 10 to $35 \%$ lignin (Sun and Cheng 2002). Hemicelluloses, the second most abundant class of biopolymers, have emerged as an immense renewable resource of biopolymers (Gírio et al. 2010). Hemicelluloses are not chemically homogeneous but rather a group of polysaccharides having a low degree of polymerization in the range of 80 to 200 (Paszner 1988). Due to challenges in isolating hemicelluloses, the extraction of hemicellulose from lignocellulosic materials such as wood is not practiced commercially.

During the production of bioethanol from lignocellulosic material, the removal of lignin and hemicellulose in pretreatments prior to biochemical conversion of the carbohydrates to sugars improves the rate and extent of conversion of the cellulose but has disadvantages in implementation due to the complexity of the recovery processes for pretreatment liquors in a greenfield operation. In addition, hemicellulose can be degraded to enzymatic inhibitors during pretreatments, which decreases the rate of conversion during enzymatic hydrolysis for bioethanol 
conversion process. For example, dilute acid pretreatment has been found to generate a significant amount of enzymatic inhibitors, such as furfural, acetic acid, and phenolic compounds (Rajan and Carrier 2014).

Xylose present in fermentation solutions can also cause problems for fermentation technology. Most of the common fermentation microorganisms are unable to convert both the hexose and the pentose contents of biomass to ethanol. For instance, Saccharomyces cerevisiae, which can utilize glucose efficiently, is tolerant of higher ethanol concentrations as well as inhibitors, but it has a low efficiency in the conversion of xylose (Huang et al. 2017). Therefore, for all the reasons above, it is beneficial to extract hemicellulose before converting cellulose to sugars for fermentation to ethanol. In addition, if a commercially viable application for hemicellulose is developed, then the overall economics of a lignocellulosic bioethanol process would be greatly improved.

Hemicellulose-based polymers can be applied as wet end additives in papermaking, substituting for starch. Hardwood xylan obtained by alkaline extraction, for instance, has been shown to be effective in improving the fiber bonding and surface sizing in papermaking (Fuhrmann and Krogerus 2009). High molar mass hemicellulose may be used in novel industrial applications such as biodegradable biopolymers and barrier films. Ongoing research in the authors' laboratory is being done to utilize hemicelluloses in absorbent and superabsorbent applications.

Alkaline treatment can be an effective process to remove hemicellulose, and it has been used in many studies for the extraction of hemicellulose from different types of biomass (Lawther et al. 1996; Vena et al. 2013) or used as a pretreatment method to increase the enzymatic convertibility of cellulose substrate (Zhao et al. 2008b; Meng et al. 2014). Alkali treatment can disrupt the cell wall of biomass efficiently through hydrolyzing uronic and acetic esters; it also can cleave the $\alpha$-ether linkages between lignin and hemicellulose and the ester bonds between lignin and/or hemicellulose and hydroxycinnamic acids (Jackson 1977). Sodium hydroxide, specifically, has been shown to be very effective for the removal of hemicellulose, as well as lignin (Sun et al. 1995; Wen et al. 2011). Xiao et al. (2001) evaluated the delignification and hemicellulose extraction yield of alkaline extraction with $1.0 \mathrm{M} \mathrm{NaOH}$ at $30{ }^{\circ} \mathrm{C}$ for $18 \mathrm{~h}$ on dewaxed maize stems, rye straw, and rice straw. They reported $78.0 \%, 68.8 \%$, and $82.1 \%$ of the original lignin, and $72.1 \%, 72.6 \%$, and $84.6 \%$ of the original hemicellulose dissolved in the solution, respectively. Alkali can promote a swollen state of the biomass and modifications to the crystalline state of the cellulose, increasing the accessibility for enzymes (Hendriks and Zeeman 2009). Higher extraction temperatures can extract higher molecular weight hemicellulose; however, high temperature can also increase the peeling reaction during alkaline extraction process. As reported by Bian et al. (2012), the highest molecular weight hemicellulose of 93,300 $\mathrm{g} \mathrm{mol}^{-1}$ extracted from sugarcane bagasse was achieved with $10 \% \mathrm{KOH}$ at $35^{\circ} \mathrm{C}$.

The structures and composition of lignocellulosic biomass vary with species, causing the extractability of hemicellulose and enzymatic hydrolysis of different species to be significantly different. In general, softwood lignocellulose is considered as the most recalcitrant material for hemicellulose extraction (and as well for enzymatic hydrolysis), which is likely due to the highly lignified structure and the nature of the lignin component. The effect of delignification on hemicellulose extraction and enzymatic hydrolysis of different species is expected to be different. It is well known that lignin is one of the major barriers for enzymatic hydrolysis; the removal of lignin usually improves enzymatic hydrolysis (Yu et al. 2011). However, little research has been 
reported on the effect of different delignification methods on hemicellulose extraction from different types of lignocellulosic biomass.

Sodium chlorite delignification $\left(\mathrm{NaClO}_{2}, \mathrm{SC}\right)$, which is used commonly in research, is effective in the removal of lignin from all types of lignocellulosic biomass; however, a certain limited amount of degradation of hemicellulose may occur during such treatment (Hubbell and Ragauskas 2010). Peracetic acid delignification (PAA) is reported to be a more selective procedure than SC (Kumar et al. 2013). In totally chlorine free bleaching (TCF), peracetic acid has been used mainly as a delignifier because of its selectivity (López et al. 2002). The selectivity of peracetic acid has been utilized to improve pulp strength by reducing the amount of less-selective bleaching chemicals while achieving the same final pulp brightness level. Also, a procedure using an alkaline aqueous alcohol mixture $(\mathrm{Ethanol} / \mathrm{NaOH})$ for delignification $(\mathrm{EN})$ has been evaluated, as a replacement for SC and PAA (Ebringerova and Heinze 2000; Ayoub et al. 2013; Jiang et al. 2014). Organic solvents may be recovered by distillation and recycled. In addition, in this process the dissolved lignin together with other dissolved components such as extractives can be recovered. However, the hemicellulose product obtained from the relatively milder EN delignification may have a higher content of lignin and degradation products than SC and PAA (Jiang et al. 2014).

In the present work, the hemicellulose extractability of three different types of lignocellulosic biomass, switchgrass (SG) poplar and pine, were evaluated, as well as the enzymatic convertibility of the cellulose-rich residues produced after the alkaline extraction. The effect of Ethanol/ $\mathrm{NaOH}$ delignification, sodium chlorite delignification, and peracetic acid delignification on alkaline hemicellulose extraction from these biomasses and the enzymatic convertibility of cellulose-rich residues were determined. The structures and properties of extracted hemicelluloses were characterized by viscosity molecular weight, FT-IR, and thermogravimetric analyzer (TGA). Interesting differences in the hemicellulose products obtained were determined for different biomass and delignification processes.

\section{MATERIAL AND METHODS}

\section{Material}

Three types of biomass, including switchgrass (Panicum virgatum, provided by the Center for Renewable Carbon, Knoxville, TN), poplar (two-year-old fast growing poplar, provided by ArborGen Inc., Ridgeville, SC), and pine (Pinus, provided by International Paper, Riegelwood, NC) were used in this research. The air dried sample was ground by a Wiley mill, and the particles sieved to obtain a size fraction between a 40 and 80 mesh $(0.420 \mathrm{~mm}$ and $0.177 \mathrm{~mm})$. The retained fraction was collected in a sealed plastic bag and stored at room temperature for subsequent treatments.

\section{Hemicellulose Extraction}

Hemicellulose was extracted from switchgrass, poplar, and pine with or without prior delignification (Fig. 1). An amount of 5 gram of raw biomass was used as starting material.

\section{Delignification}

Ethanol and Sodium Hydroxide Method (EN): An aqueous alcohol treatment was used to remove lignin under atmospheric pressure. The aqueous alcohol consisted of $70 \%(\mathrm{v} / \mathrm{v})$ ethanol 
and $30 \%(\mathrm{v} / \mathrm{v}) \mathrm{NaOH}$ solution $(1 \%(\mathrm{w} / \mathrm{w}))$. The treatment was conducted in a $250 \mathrm{~mL}$ boiling flask equipped with condenser at a liquid/solids ratio of 20 with stirring. The temperature was controlled at $75^{\circ} \mathrm{C}$ using an oil bath. After $2 \mathrm{~h}$, the suspension was allowed to cool to room temperature and filtered to collect the delignified sample \#2. The sample was washed with $70 \%$ ethanol to remove the soluble lignin.

Sodium Chlorite Method (SC): The biomass was delignified with sodium chlorite in acidic condition at $75{ }^{\circ} \mathrm{C}$ for $4 \mathrm{~h}$. The treatment was conducted in a $500 \mathrm{~mL}$ Erlenmeyer flasks in a water bath with an initial liquid to solids ratio of 30 . An amount of $0.3 \mathrm{~g} / \mathrm{g}$ solids of sodium chlorite $\left(\mathrm{NaClO}_{2}\right)$ and $0.25 \mathrm{~mL} / \mathrm{g}$ solids of acetic acid were added initially. The slurry was thoroughly mixed by shaking the flasks, and then a $50 \mathrm{~mL}$ Erlenmeyer flask was inverted in the neck of the reaction flask. The flasks were incubated in a fume hood with intermittent mixing, and fresh charges of sodium chlorite and acetic acid were added to the reaction every $1 \mathrm{~h}$ for up to $4 \mathrm{~h}$. After reaction, the slurry was vacuum filtered and washed with DI water until the $\mathrm{pH}$ of the filtrate was nearly neutral.

Peracetic Acid Method (PAA): Peracetic acid delignification was performed at $25{ }^{\circ} \mathrm{C}$ and $5 \%$ (w/w) solids loadings (Kumar et al. 2013). The reaction was conducted in $500 \mathrm{~mL}$ Erlenmeyer flasks and heated in a temperature controlled water bath. A peracetic acid loading of $5 \mathrm{~g} / \mathrm{g}$ dry solids and a reaction time of $48 \mathrm{~h}$ were used. After the reaction, the slurry was vacuum filtered, and the solids were washed with room temperature deionized water until the filtrate $\mathrm{pH}$ was close to neutral.

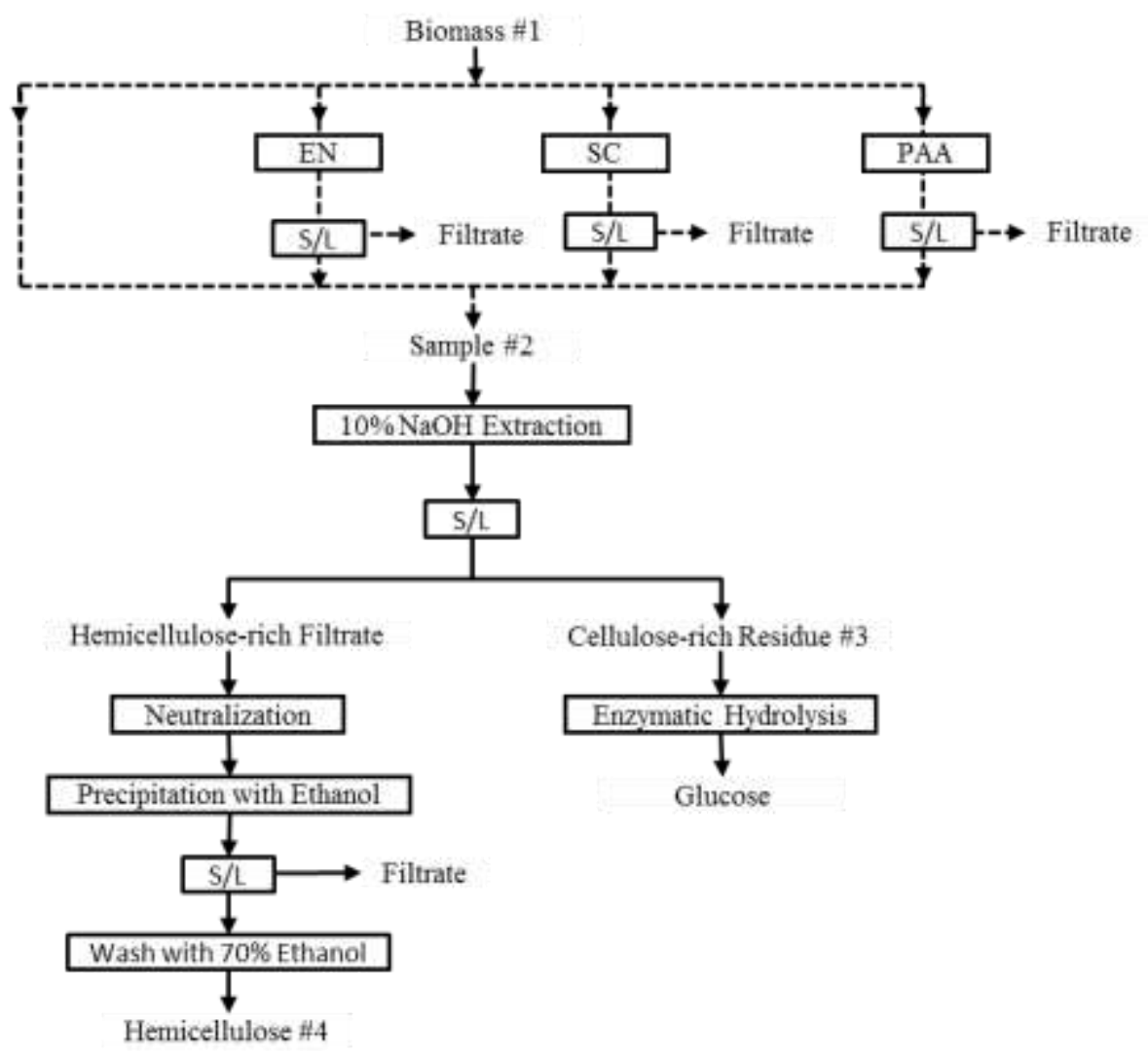

Fig. 1. Scheme of hemicellulose extraction and enzymatic hydrolysis. Hemicellulose was extracted form untreated samples, Ethanol/ $\mathrm{NaOH}$ (EN) delignified samples, sodium chlorite (SC) delignified samples and peracetic acid (PAA) delignified samples 


\section{Alkaline extraction}

As shown in Fig. 1, hemicellulose was isolated using 10\% (w/w) $\mathrm{NaOH}$ from untreated samples (\#1) and delignified samples (\#2). The alkaline extraction was conducted at $50{ }^{\circ} \mathrm{C}$ for $3 \mathrm{~h}$ with a liquid/solids ratio of 20. At the end of the extraction period, the suspension was filtered with house vacuum on Whatman GF/A glass microfiber filter paper to collect the filtrate containing hemicellulose. The cellulose-rich residues \#3 was washed with deionized water and collected for chemical composition analysis and the enzymatic hydrolysis. The $\mathrm{pH}$ of hemicellulose enriched filtrate was adjusted to 5.5 with $6 \mathrm{M}$ acetic acid then 2.5 volumes of $95 \%$ ethanol (v/v) were added to precipitate the hemicellulose. The pellets of hemicellulose were washed with $70 \%$ ethanol and then freeze-dried to yield hemicellulose powder \#4.

\section{Enzymatic Hydrolysis}

The enzymatic convertibility of cellulose-rich residues \#3 isolated after the hemicellulose extraction process was evaluated. Cellulase (Cellic ${ }^{\circledR}$ CTec2) and hemicellulase (Cellic® HTec2) provided by Novozymes North America (Franklinton, NC) were used. The enzymatic hydrolysis was conducted following a procedure reported by the team (Geng et al. 2015). Enzymatic hydrolysis was carried out at $5 \%$ solids loading with a total mass of 20 gram in a $50 \mathrm{~mL}$ conical tube at $50{ }^{\circ} \mathrm{C}$ with shaking at $180 \mathrm{rpm}$ for $96 \mathrm{~h}$. A $1 \mathrm{mM}$ sodium acetate buffer solution ( $\mathrm{pH} 4.8$ ) was used for $\mathrm{pH}$ adjustment and microbial control. Enzyme dosage was 5 FPU/g-substrate. The residues and hydrolysate after the hydrolysis were separated via micro-centrifugation for $10 \mathrm{~min}$ at 13,000 rpm, and the monomeric sugars were analyzed by HPLC. All the determinations were conducted in duplicate.

\section{Chemical Composition Analysis}

Lignin and carbohydrate content were evaluated using the NREL protocol for the raw materials \#1, delignified samples \#2, cellulose-rich residues \#3, and hemicellulose \#4 (Sluiter et al. 2008).

The sugar content was determined on a high-performance liquid chromatography (HPLC) system (Agilent 1200, Agilent, Santa Clara, CA, USA) equipped with an Agilent guard column, degasser, pump, and refractive index detector (RID, following a modified NREL Laboratory Analytical Procedure) (Sluiter et al. 2008). Calcium carbonate was used to adjust the $\mathrm{pH}$ of the acid hydrolysis hydrolysate. The acid hydrolysis hydrolysate and enzymatic hydrolysis hydrolysate samples were filtered using a $0.22 \mu \mathrm{m}$ nylon syringe filter before being injected into HPLC. The column temperature of the HPLC was $80{ }^{\circ} \mathrm{C}$. HPLC grade Milli-Q water was used as the mobile phase. The samples of hydrolysate were analyzed with a $20 \mathrm{uL}$ injection volume and $0.5 \mathrm{~mL} / \mathrm{min}$ flow rate.

\section{Viscosity Molecular Weight}

To characterize the extracted hemicelluloses, the average viscosity molecular weight was calculated. For this it was necessary to determine the intrinsic viscosity $([\eta])$ obtained by combined application of Huggins and Kramer equations 1 and 2,

$$
\begin{aligned}
& \frac{\eta_{s p}}{c}=[\eta]+k_{1}[\eta]^{2} c \\
& \frac{\ln \eta_{r}}{c}=[\eta]+k_{2}[\eta]^{2} c
\end{aligned}
$$


where the specific viscosity $\eta_{\mathrm{sp}}=\left(\eta-\eta_{\mathrm{s}}\right) / \eta_{\mathrm{s}}$, relative viscosity $\eta_{\mathrm{r}}=\eta / \eta_{\mathrm{s}}$, and $\eta$ and $\eta_{\mathrm{s}}$ are the viscosities of the solution and the solvent respectively. A concentration of $0.4 \mathrm{M}$ cupriethylenediamine (CED) solution was used. The specific viscosity $\left(\eta_{\mathrm{sp}}\right)$ of hemicelluloses within a concentration range from $0.1 \mathrm{~g} / \mathrm{L}$ to $0.5 \mathrm{~g} / \mathrm{L}$ were measured using a capillary viscosimeter at $25{ }^{\circ} \mathrm{C}$. Then the intrinsic viscosity was calculated based on Eqs. 1 and 2. The number average degree of polymerization $\left(P_{\mathrm{n}}\right)$ of hemicellulose was calculated from the intrinsic viscosity (Table 2) based on Staudinger-Mark-Houwink equation 3,

$$
[\eta]=K \bar{P}_{n}^{a}
$$

where $K=2.2 \times 10^{-2}$ and $a=0.72$ are empirical constants for xylan in 0.4 M CED solution (Koshijima et al. 1965). As reported by the cited authors, hemicellulose had a number-average molecular weight of $31,500 \mathrm{~g} / \mathrm{mole}$, corresponding to a degree of polymerization of 200 . The viscosity average molecular weight $\bar{M}_{v}$ can be calculated by Eq. 4 .

$$
\bar{M}_{v}=31,500 \times P_{n} / 200
$$

\section{FT-IR Spectroscopy}

FT-IR spectra of hemicelluloses extracted from SC delignified samples were done with a Frontier FT-IR spectrometer (PerkinElmer Inc., USA). An amount of $200 \mathrm{mg}$ of $\mathrm{KBr}$ was mixed with about $20 \mathrm{mg}$ of hemicellulose and ground together using a mortar-pestle. The mixture was then pelletized using a PerkinElmer 15 ton manual hydraulic press. The spectra were recorded in the range of 4000 to $600 \mathrm{~cm}$ with 32 scans per sample. The $\mathrm{KBr}$ background was subtracted from the spectra.

\section{TGA}

Thermal stability of hemicelluloses extracted from SC delignified sample was determined using a TGA Q500 (TA Inc., New Castle, DE). About $15 \mathrm{mg}$ of samples were placed in a platinum pan and run from room temperature to $600{ }^{\circ} \mathrm{C}$ at a rate of $10^{\circ} \mathrm{C} / \mathrm{min}$ in a nitrogen atmosphere.

\section{RESULTS AND DISCUSSION}

\section{Composition of Raw Materials}

The group of materials termed hemicellulose includes polysaccharides of different structures containing glucose, xylose, mannose, galactose, arabinose, and so on, in various amounts or traces dependent on the natural source (Ebringerova and Heinze 2000). As shown in Table 1, among the three types of biomass studied herein, switchgrass had the highest hemicellulose (sum of xylan, galactan, arabinan, and mannan) content $(32.8 \%)$ and the lowest lignin content $(20.1 \%)$. Pine had the highest lignin content $(29.9 \%)$. Lignin present in the biomass is expected to limit both the extractability of hemicellulose and the enzymatic convertibility of the cellulose-rich residues, supposedly because of the physical barrier and chemical linkages between hemicellulose and lignin and cellulose and lignin. A relatively high ratio of xylan $(72.5 \%)$ in hemicellulose is an important feature of switchgrass. As shown in Fig. 2, 65.4\% of the hemicellulose present in poplar was xylan. The 4-O-methyl-D-glucurono-D-xylan represents more than $90 \%$ of the hemicellulose component in hardwoods and herbal plants of the temperate zone (Ebringerová 2005). In softwoods, acetylated galactoglucomannan is the main hemicellulose with 
mannan being predominant in pine (Peng et al. 2012b). Generally, (L-arabino)-D-glucurono-Dxylans is the second most abundant hemicellulose component in softwood (Ebringerová 2005).

Table 1. Main Chemical Composition (\% of the raw material) of Switchgrass, Poplar, and Pine

\begin{tabular}{|c|c|c|c|}
\hline Chemical Composition, \% & SG & Poplar & Pine \\
\hline Lignin & 20.1 & 24.9 & 29.9 \\
\hline Glucan & 39.1 & 40.7 & 43.1 \\
\hline Xylan & 25 & 14.2 & 7.5 \\
\hline Galactan & 2.1 & 1.6 & 2.5 \\
\hline Arabinan \& Mannan & 5.7 & 5.9 & 13.3 \\
\hline Ash & 1.7 & 0.1 & 0.3 \\
\hline
\end{tabular}

\section{Efficiency of Delignification}

A robust biorefinery would take biomass and utilize its different components to make multiple coproducts. This might include cellulose, lignin, and hemicellulose products and fractionated components of such materials. In this regard, since lignin can cause physical and chemical barriers to hemicellulose extraction and enzymatic hydrolysis, delignification may be a key step for both hemicellulose extraction and enzymatic hydrolysis of the extraction residues and promote the biorefinery concept. In order to minimize the degradation of carbohydrate, a mild delignification method, aqueous alcohol (Ethanol/1\% NaOH, 7:3) delignification at atmospheric pressure was one method evaluated to remove lignin. As shown in Fig. 2 (A-C), most of the carbohydrate remained in the delignified samples EN_\#2. However, the lignin removal efficiency of such treatment was limited and varied with the type of biomass. An amount of $22.4 \%$ of the original lignin could be removed from switchgrass; however, very low amounts of lignin were removed from poplar and pine, $4 \%$ and $11 \%$, respectively. Aqueous alcohol delignification requires a very high temperature $\left(100\right.$ to $250{ }^{\circ} \mathrm{C}$ ) to result in an effective delignification (Muurinen 2000). Increasing temperature can increase the degree of delignification; however, this will also degrade the hemicellulose (Demirba 1998).

$\mathrm{SC}$ is very effective in removing lignin from all types of biomass. As shown for SC_\#2 in Fig. 2 (A-C), 89.1\%, 92.0\%, and $87.0 \%$ of the lignin was removed with sodium chlorite delignification from switchgrass, poplar, and pine, respectively. However, a significant amount of degradation of carbohydrate, especially hemicellulose, occurred during such treatment. There were $5.9 \%, 1.7 \%$, and $11.1 \%$ of the original glucan degraded from switchgrass, poplar, and pine, respectively, Fig. 2. A high percentage of hemicellulose was removed during $\mathrm{NaClO}_{2}$ delignification, $24.7 \%, 18.4 \%$, and $33.5 \%$ switchgrass, poplar, and pine, respectively. As reported by Kumar et al. (2013), $\mathrm{NaClO}_{2}$ delignification was less selective on untreated lignocellulosic biomass and resulted in about $18 \%$ loss of the glucan, $38 \%$ loss of the xylan, and $30 \%$ loss of the arabinan for switchgrass. The non-negligible degradation of hemicellulose results in a lower molecular weight (see later). The chlorite procedure is selective in removing lignin only during the first $60 \%$ of delignification; a certain amount of hemicellulose is expected to degrade in the later stage (Ahlgren and Goring 1971).

It has been reported that PAA delignification was more selective than SC delignification (Kumar et al. 2013). PAA is recognized as a powerful oxidizing agent that can oxidize the aromatic ring in lignin, generating dicarboxylic acid and their lactones (Zhao et al. 2008a). This delignification method removed $90 \%, 98.4 \%$, and $81.6 \%$ of lignin from switchgrass, poplar, and 
pine, respectively (Fig. 2). During PAA treatment, 9.2\%, 7.6\%, and $12.8 \%$ of glucan and $24.1 \%$, $24.9 \%$, and $30.0 \%$ of hemicellulose were solubilized from switchgrass, poplar, and pine, respectively.
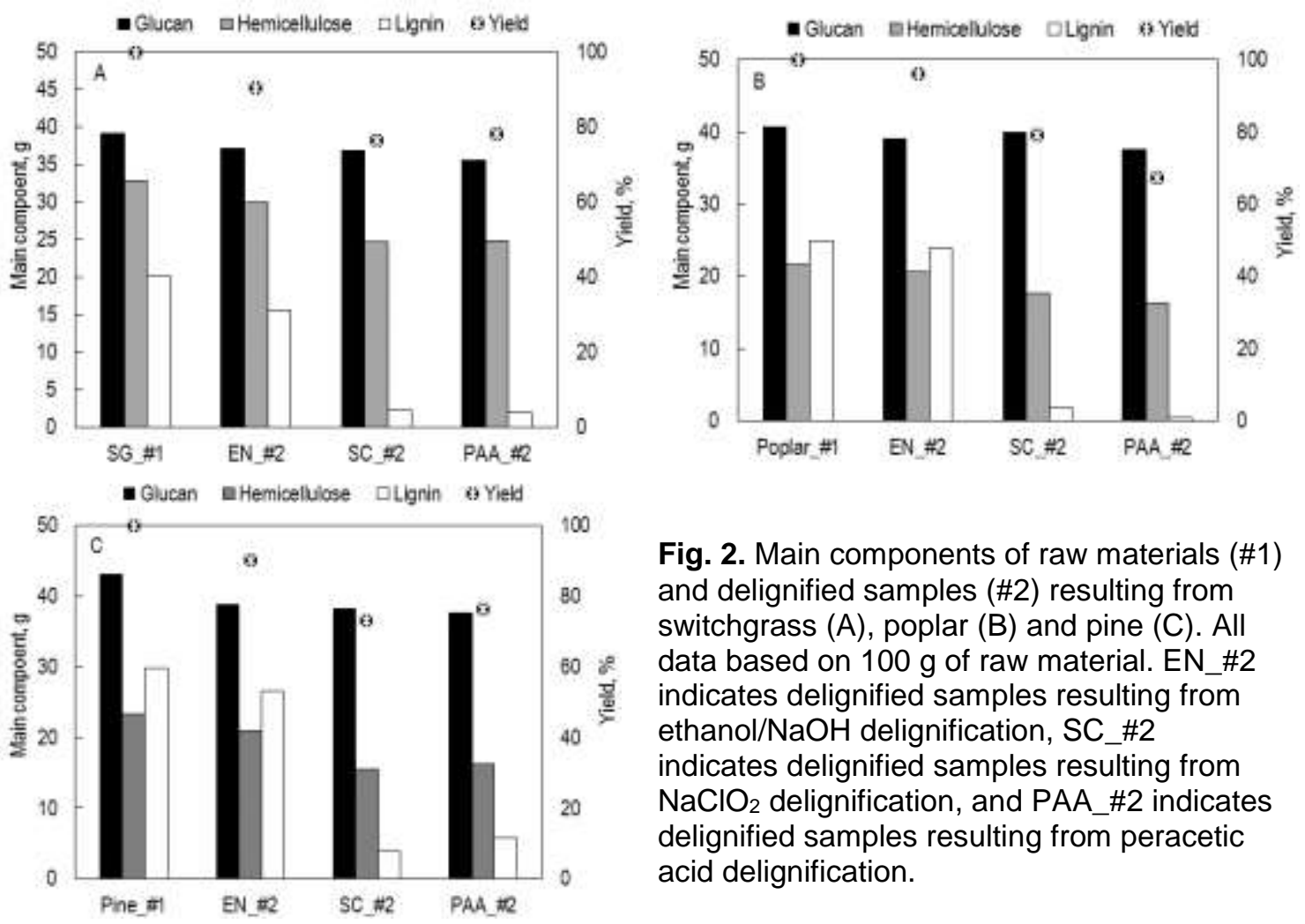

Fig. 2. Main components of raw materials (\#1) and delignified samples (\#2) resulting from switchgrass (A), poplar (B) and pine (C). All data based on $100 \mathrm{~g}$ of raw material. EN_\#2 indicates delignified samples resulting from ethanol/NaOH delignification, SC_\#2 indicates delignified samples resulting from $\mathrm{NaClO}_{2}$ delignification, and PAA_\#2 indicates delignified samples resulting from peracetic acid delignification.

There was slightly more glucan removed for all three types of biomass during PAA delignification relative to SC delignification (Fig. 2). The degradation of hemicellulose during PAA delignification was similar to SC. Overall, PAA delignification showed a similar or very slightly lower selectivity to SC in this study. PAA had the best effectiveness on the poplar biomass, in which $98.4 \%$ of lignin, $7.6 \%$ of glucan and $30.0 \%$ of hemicellulose were removed. The carbohydrate degradation with PAA here is reasonable when compared to that reported by Yin $e t$ al. (2011), in which $10 \%$ of glucan and $13 \%$ of xylan were degraded along with a $57 \%$ of lignin removal from aspen.

\section{Effect of Delignification on Hemicellulose Extraction Efficiency}

Hemicellulose was extracted from the no-delignification samples, ethanol/sodium hydroxide (EN) delignified samples, $\mathrm{NaClO}_{2}$ delignified samples (SC), and PAA delignified samples. As shown in Table 2, even without delignification, a reasonable extraction yield of hemicellulose on the starting raw biomass material of $24.8 \%$ could be achieved from switchgrass. An amount of $55.5 \%$ of the hemicellulose was extracted from the original hemicellulose present in the raw material. This result is in reasonable agreement with a report that a yield of $18 \%$ of hemicellulose was extracted from untreated switchgrass with a lower $\mathrm{NaOH}$ concentration $(7 \%$ $(\mathrm{w} / \mathrm{w}))$ at a higher temperature $\left(85^{\circ} \mathrm{C}\right)($ Stoklosa and Hodge 2012$)$. 
Table 2. Hemicellulose Extraction Efficiency for Individual Sugars and the Overall Extraction

\begin{tabular}{|c|c|c|c|c|c|c|}
\hline \multirow{4}{*}{} & Delignification & Yield ${ }^{* 1}, \%$ & \multicolumn{4}{|c|}{ Extraction Efficiency ${ }^{* 2}, \%$} \\
\cline { 3 - 7 } & & & Xylan & Galactan & $\begin{array}{c}\text { Arabinan \& } \\
\text { Mannan }\end{array}$ & $\begin{array}{c}\text { Overall } \\
\text { Efficiency }\end{array}$ \\
\hline \multirow{4}{*}{ SG } & NO & 24.8 & 60.8 & 19.0 & 45.6 & 55.5 \\
\cline { 2 - 7 } & EN & 24.5 & 60.4 & 19.0 & 40.4 & 54.3 \\
\cline { 2 - 7 } & SC & 28.8 & 72.8 & 19.0 & 49.1 & 65.2 \\
\cline { 2 - 7 } Poplar & PAA & 31.1 & 74.8 & 19.0 & 45.6 & 66.2 \\
\cline { 2 - 7 } & NO & 15.8 & 71.8 & 6.3 & 11.9 & 50.7 \\
\cline { 2 - 7 } & EN & 14.7 & 64.1 & 6.3 & 15.3 & 46.5 \\
\cline { 2 - 7 } & SC & 23.7 & 90.1 & 18.8 & 25.4 & 67.3 \\
\hline \multirow{3}{*}{ Pine } & PAA & 22.1 & 90.1 & 18.8 & 23.7 & 66.8 \\
\cline { 2 - 7 } & NO & 1.5 & 5.3 & 4.0 & 2.3 & 3.4 \\
\cline { 2 - 7 } & EN & 1.7 & 5.3 & 4.0 & 3.8 & 4.3 \\
\cline { 2 - 7 } & SC & 21.7 & 62.7 & 40.0 & 45.1 & 50.2 \\
\hline
\end{tabular}

*1: Yield of precipitated hemicellulose stream is based on the raw biomass before delignification total weight. Note that there were mass losses during precipitation due to some lignin, low molecular weight sugars and extractives not precipitating in ethanol.

*2: Extraction efficiency for individual sugars equals the amount of the individual sugar in extracted hemicellulose sample \#4 relative to the amount of this sugar in the original material \#1; Extraction efficiency for overall efficiency equals the total amount of Xylan+Galactan+Arabinan and Mannan in extracted hemicellulose sample \#4 relative to the total amount of Xylan+Galactan+Arabinan in the original material \#1.

Compared with no delignification, EN delignification did not result in higher hemicellulose yields $(24.5 \%)$ from switchgrass, even though $22.4 \%$ of the original lignin was removed during a prior delignification treatment. A high hemicellulose extraction yield of $28.8 \%$ of switchgrass was achieved from the $\mathrm{NaClO}_{2}$ delignified sample, in which $89.1 \%$ of lignin was removed from the raw material in a previous step. The highest hemicellulose extraction yield achieved from switchgrass was $31.1 \%$, resulting from the PAA delignified sample.

There are two ways to explain the slightly higher yield of hemicellulose resulting from a PAA-delignified sample. One explanation is that the degradation of hemicellulose during PAA delignification treatment was slightly lower than that of SC delignification, which resulted in a higher hemicellulose extraction efficiency. Another explanation is that some lignin was present in the extracted hemicellulose sample and that this contributed to the total hemicellulose enriched sample yield. As shown in Fig. 3, the hemicellulose product extracted from PAA delignified sample had a slightly higher lignin content $(0.5 \%)$ than that extracted from SC delignified sample $(0 \%)$. The removal of lignin with SC delignification and PAA delignification increased the extraction efficiency significantly with switchgrass (Table 2), which indicated that the linkages between xylan and lignin were a main barrier that limited the hemicellulose extractability of switchgrass. This suggests that breaking the lignin-xylan complex linkages in switchgrass may increase the hemicellulose extractability.

A considerable amount of hemicellulose $(15.8 \%$ yield on starting biomass and $50.7 \%$ overall hemicellulose extraction) was extracted from poplar without delignification (Table 2). Only $4 \%$ of lignin was removed with EN delignification, which resulted in a slightly lower hemicellulose extraction efficiency (46.5\%), probably because of a slight degradation of hemicellulose during such treatment. The highest hemicellulose extraction efficiency of $67.3 \%$ 
was achieved with $\mathrm{NaClO}_{2}$ delignification, which resulted in a whiter color of the extracted hemicellulose. The hemicellulose extraction yield on original biomass $(22.1 \%)$ resulting from PAA delignification was slightly lower than that of SC delignification (23.7\%) because more hemicellulose was degraded during PAA treatment. The increasing percentage of hemicellulose extraction yield resulting from SC and PAA delignification of poplar was more significant than switchgrass, which indicates the barrier of lignin present in hardwood was more important than that for the perennial plant switchgrass.

In the case of pine, without delignification or with EN delignification, less than $5 \%$ of hemicellulose could be extracted, Table 2 . However, $50.2 \%$ and $47.5 \%$ of hemicellulose could be extracted after SC and PAA delignification of the pine, respectively. In contrast to switchgrass and poplar, the hemicellulose present in pine was only appreciably extractable following an efficient delignification step. This may be caused by a higher lignin content in softwoods (Table 1), in which the polysaccharides in the secondary wall are more encrusted and less accessible to the alkali. The lignin-carbohydrate complexes present in lignocellulosic biomass could be another reason that limited the hemicellulose extractability.

With SC delignification, $86.6 \%, 82.5 \%$ and $75.5 \%$ of the hemicellulose present in the delignified biomass was extracted from the delignified switchgrass, poplar and pine, respectively. The reason that the extraction efficiency of the $\mathrm{NaClO}_{2}$ delignified pine was lower than the others could be related to the different structure of the main type of hemicellulose present in the different species. The main type of hemicellulose presented in softwood is galactoglucomannans, which has a more linear structure than hardwood and grass hemicelluloses, contributing to lower solubility and a lower extraction yield (Ebringerová 2005).

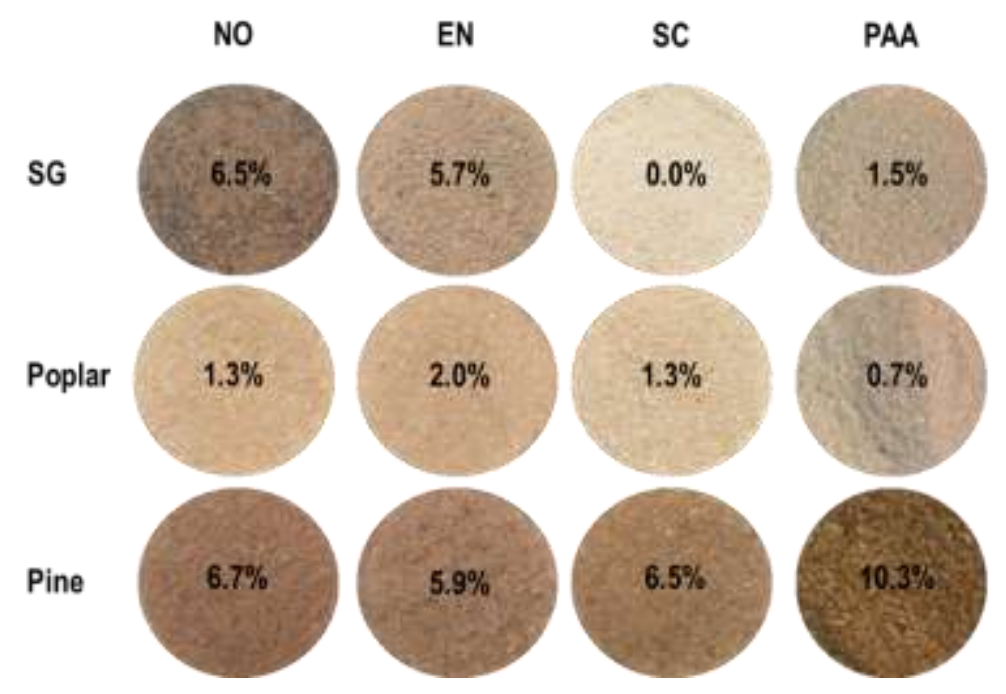

Fig. 3. Visual appearance and lignin content of hemicellulose products extracted from switchgrass, poplar, and pine

\section{Effect of Delignification on Hemicellulose Purity}

Delignification often increases the hemicellulose extractability of biomass, but it may also impact the purity of hemicellulose products. As shown in Fig. 3, the hemicellulose extracted from untreated biomass had a darker color and higher lignin content than those extracted from delignified samples. EN delignification did not result in higher hemicellulose yields, but it produced a lighter color of extracted hemicellulose relative to the no delignification samples due 
to lower lignin content. Hemicellulose extracted from SC delignified switchgrass had the lightest color and an undetectable amount of lignin. In contrast to no delignification and EN delignification samples, SC and PAA achieved a higher hemicellulose yield and purity, and the hemicellulose products had a lighter color.

\section{Effect of Delignification on Hemicellulose Molecular Weight}

Both SC and PAA delignification processes can remove lignin efficiently; however, a significant amount of degradation of hemicellulose occurred during the delignification process, resulting in a lower number average molecular weight of extracted hemicelluloses (Table 3). SC and PAA delignification showed a more significant effect on the molecular weight of hemicelluloses extracted from poplar. As shown in Table 3, compared with the molecular weight $(26,400)$ of hemicellulose extracted form untreated poplar, the molecular weight of hemicellulose extracted from SC delignified poplar decreased to 14,100. The degradation of hemicellulose during SC and PAA delignification were similar; however, the viscosity molecular weight of hemicellulose resulted from PAA delignification was slightly higher than that extracted from SC delignified samples. This can be explained by the hemicellulose extracted from PAA delignified having a more linear structure. As shown in Table 2, the PAA delignified hemicellulose had higher xylan (backbone component) yield and lower arabinan and mannan (side chain component) yield, which would indicate more linearity. At the same molecular weight, a linear polymer structure is expected to have a higher viscosity than a branched polymer.

Table 3. Intrinsic Viscosity $([\eta])$, Number Average Degree of Polymerization $\left(P_{n}\right)$, and Number Average Molecular Weight $\left(M_{\mathrm{w}}\right)$ of the Extracted Hemicelluloses

\begin{tabular}{|c|c|c|c|c|}
\hline & Delignification & {$[\eta]$} & $P_{\mathrm{n}}$ & $M_{\mathrm{w}}$ \\
\hline SG & NO & 0.81 & 150 & 23,600 \\
\cline { 2 - 5 } & $\mathrm{EN}$ & 0.78 & 143 & 22,500 \\
\cline { 2 - 5 } & $\mathrm{SC}$ & 0.72 & 128 & 20,200 \\
\cline { 2 - 5 } & $\mathrm{PAA}$ & 0.81 & 149 & 23,400 \\
\hline Poplar & $\mathrm{NO}$ & 0.88 & 167 & 26,400 \\
\cline { 2 - 5 } & $\mathrm{EN}$ & 0.84 & 158 & 24,900 \\
\cline { 2 - 5 } & $\mathrm{SC}$ & 0.56 & 89 & 14,100 \\
\cline { 2 - 5 } & $\mathrm{PAA}$ & 0.60 & 99 & 15,500 \\
\hline Pine & $\mathrm{NO}$ & 0.62 & 103 & 16,300 \\
\cline { 2 - 5 } & $\mathrm{EN}$ & 0.60 & 100 & 15,700 \\
\cline { 2 - 5 } & $\mathrm{SC}$ & 0.59 & 97 & 15,300 \\
\cline { 2 - 5 } & $\mathrm{PAA}$ & 0.60 & 100 & 15,700 \\
\hline
\end{tabular}

The molecular weight of extracted pine hemicellulose was much lower than switchgrass and poplar for all samples. Since only a very limited amount of hemicellulose can be extracted from the untreated pine, the true molecular weight of the native, un-degraded softwood hemicellulose is not known.

\section{FT-IR Spectra}

The chemical structure of hemicelluloses extracted from SC delignified samples was analyzed using FTIR through pelleting the sample with KBr powder. As shown in Fig. 4, there was a strong absorption band at $\sim 1038 \mathrm{~cm}^{-1}$ for all three hemicelluloses. As reported by Kačuráková et al. (2000), each particular polysaccharide has a specific band maximum in the 1200 
to $1000 \mathrm{~cm}^{-1}$ region, which is dominated by ring vibrations overlapped with stretching vibrations of $(\mathrm{C}-\mathrm{OH})$ side groups and the $(\mathrm{C}-\mathrm{O}-\mathrm{C})$ glycosidic bond vibration. There are slight differences of absorption of the linkages between different backbone units. The linear and branched (1-4)- $\beta$ xylans such as glucuronoxylan and arabinoxylans showed the main band maximum at about 1047 $\mathrm{cm}^{-1}$. The glucomannan showed in addition to the $1034 \mathrm{~cm}^{-1}$ glucan band a further band at 1064 $\mathrm{cm}^{-1}$ due to the mannose units. The absorption band of $984 \mathrm{~cm}^{-1}$ showed in the spectral of swtichgrass and poplar hemicellulose indicates the presence of arabinosyl side chain in these two hemicelluloses (Carvalho 2015). However, there are no arabinosyl units in pine hemicellulose. The dominance of $\beta$-glycosidic linkages between the xylose units or glucose and mannose units were evidenced by the presence of a sharp band at $897 \mathrm{~cm}^{-1}$ (Gupta et al. 1987). The absorption band of $3350 \mathrm{~cm}^{-1}$ contributed to the hydroxyl stretching vibration of hemicelluloses (Sun et al. 2004). The absorption band of $2881 \mathrm{~cm}^{-1}$ was related to $\mathrm{C}-\mathrm{H}$ stretching vibrations caused by the water involved in the hydrogen bonding (Sun et al. 2004). The vibration of ionized carboxyl group absorb at 1590 to $1550 \mathrm{~cm}^{-1}$ ( $\left.v_{\mathrm{a}}(\mathrm{COO}-)\right)$ and 1410 to $\left.1350 \mathrm{~cm}^{-1} v_{\mathrm{s}}(\mathrm{COO}-)\right)$, which are overlapped with other absorption bands. Water present in hemicelluloses have absorption at $1600 \mathrm{~cm}^{-1}$ (Kacurakova et al. 2000). Since there are low amount of lignin present in extracted hemicelluloses, the aromatic skeletal vibration can have a slight band at $\sim 1510 \mathrm{~cm}^{-1}$.

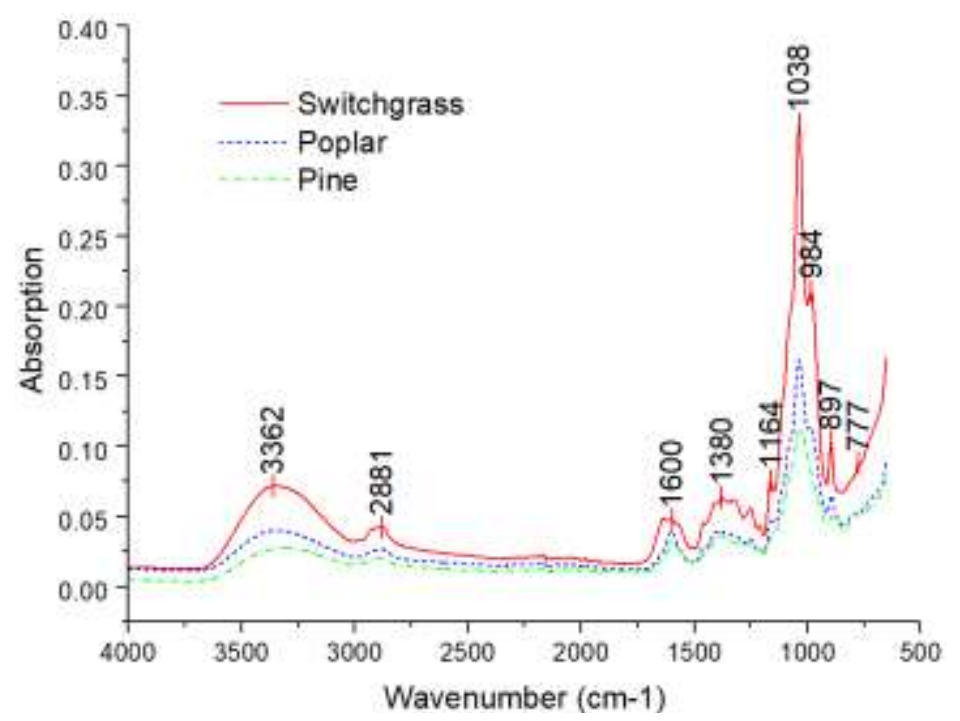

Fig. 4. The FT-IR spectra of hemicelluloses extracted from SC delignified switchgrass, poplar, and pine

\section{TGA}

Thermogravimetric analysis (TGA) was used to study the thermal behavior of hemicelluloses extracted from SC delignified samples (Fig. 5). The derivative of the weight loss versus temperature (DTG) curves of hemicelluloses show two weight loss regions, a minor weight loss at 200 to $250{ }^{\circ} \mathrm{C}$ and a major weight loss at 250 to $300{ }^{\circ} \mathrm{C}$. The minor weight loss at 200 to $250{ }^{\circ} \mathrm{C}$ contributed to the loss of bonded water and dehydration. The maximum rate of weight loss of hemicelluloses was also observed between $260{ }^{\circ} \mathrm{C}$ and $290{ }^{\circ} \mathrm{C}$, which is caused by the concurrent hemicelluloses degradation processes such as depolymerization and decomposition of glycosyl units, followed by the formation of a charred residue (Peng et al. 2012a). The higher molecular weight of hemicellulose extracted from SC delignified switchgrass may have resulted in a higher thermal stability than the other hemicelluloses (Table 3). 


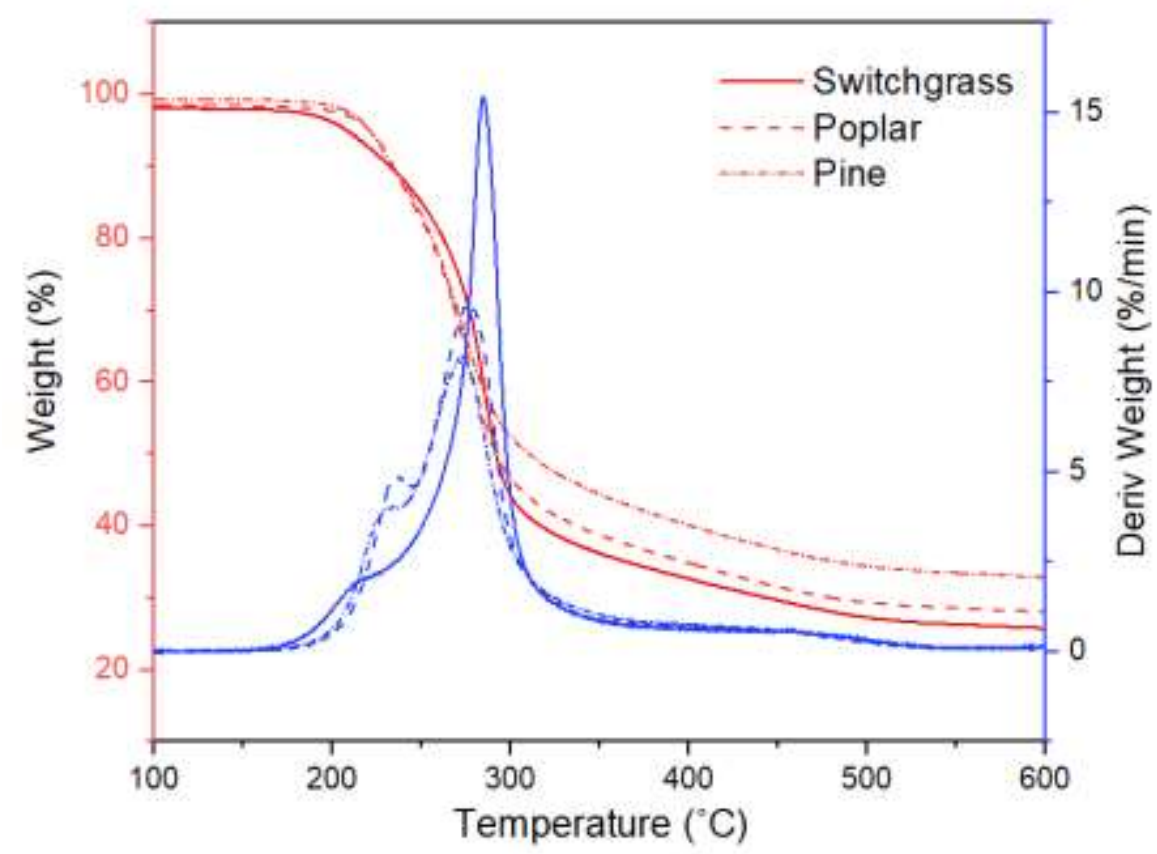

Fig. 5. Thermograms of hemicelluloses extracted from SC delignified switchgrass, poplar, and pine

\section{Effect of Hemicellulose Extraction Processes on Enzymatic Convertibility of Cellulose-rich Residues}

In order to fully utilize lignocellulosic biomass and improve the economics of a biorefinery that includes a hemicellulose extraction process, the cellulose-rich residues resulting from the delignification and/or hemicellulose extraction process (Fig. 1) might be used to produce lignocellulosic, non-food based sugars. To examine this, the glucose conversion of the celluloserich residues and the overall conversion efficiencies of glucose based on the raw biomass were evaluated to investigate the effect of delignification and hemicellulose extraction process on the enzymatic convertibility of the cellulose-rich residues. As shown in Table 4, an efficient prior delignification and an alkaline extraction could result in a very high glucan content in the residues. Enzyme hydrolysis was performed on the residues for 96 hours at 5\% solids with very low enzyme charge, 5 FPU/gram substrate. The results indicate that the steps taken in hemicellulose extraction result in cellulose-rich residues that are readily converted to sugar by enzyme hydrolysis, Table 4. Further, the sugar stream produced was a relatively pure glucose stream with very little xylose and other sugars (Table 4), due to the removal of other sugars during hemicellulose extraction. This relatively pure glucose stream would allow a subsequent fermentation process to be simple and efficient. 
Table 4. Yield ${ }^{* 1}$ and Main Chemical Composition of Cellulose-rich Residues ${ }^{* 2}$ Achieved with Different Delignification Methods and Hemicellulose Extraction and the Concentration of Sugars in the Sugar Stream Resulting from Enzymatic Hydrolysis of Cellulose-rich Residues

\begin{tabular}{|c|c|c|c|c|c|c|c|c|}
\hline & \multirow[t]{2}{*}{ Pretreatment } & \multicolumn{4}{|c|}{$\begin{array}{l}\text { Main chemical composition of cellulose- } \\
\text { rich residues, \% }\end{array}$} & \multicolumn{2}{|c|}{$\begin{array}{c}\text { Sugar } \\
\text { concentration in } \\
\text { sugar stream, } \\
\mathrm{mg} / \mathrm{mL}\end{array}$} & \multirow{2}{*}{$\begin{array}{c}\text { Glucose } \\
\text { conversion } \\
\%\end{array}$} \\
\hline & & Yield & Lignin & Glucan & Hemicellulose & Glucose & $\begin{array}{c}\text { Other } \\
\text { sugars }^{\star 3}\end{array}$ & \\
\hline \multirow{4}{*}{ SG } & $\mathrm{NO} E$ & 51.9 & 15.1 & 61.3 & 11.4 & 33.4 & 5.5 & 93.3 \\
\hline & EN_E & 53.9 & 13.5 & 62.4 & 13.5 & 33.2 & 6.2 & 91.1 \\
\hline & SC_E & 36.0 & 1.4 & 84.5 & 4.9 & 48.7 & 2.3 & 98.6 \\
\hline & PAA_E & 33.2 & 0.0 & 92.5 & 3.1 & 48.7 & 2.6 & 90.6 \\
\hline \multirow{4}{*}{ Poplar } & $\mathrm{NO} E$ & 71.2 & 31.8 & 48.7 & 7.9 & 16.3 & 5.4 & 57.2 \\
\hline & EN_E & 72.6 & 31.5 & 49.5 & 8.6 & 17.1 & 5.0 & 59.0 \\
\hline & $\mathrm{SCE}$ & 38.6 & 1.0 & 86.3 & 6.0 & 52.4 & 2.7 & 99.1 \\
\hline & PAAEE & 31.7 & 0.0 & 96.3 & 2.5 & 47.7 & 2.6 & 87.4 \\
\hline \multirow{4}{*}{ Pine } & $\mathrm{NO} E$ & 93.9 & 29.6 & 41.3 & 18.8 & 5.5 & 3.9 & 22.8 \\
\hline & ENEE & 83.8 & 29.7 & 41.7 & 19.0 & 7.0 & 4.6 & 28.6 \\
\hline & SC_E & 43.5 & 0.3 & 78.0 & 8.6 & 42.4 & 5.4 & 92.9 \\
\hline & PAA_E & 40.3 & 1.7 & 80.0 & 8.9 & 36.9 & 6.2 & 78.8 \\
\hline \multicolumn{9}{|c|}{$\begin{array}{l}\text { *1: Based on raw material before delignification total weight } \\
\text { *2: Based on oven dry cellulose-rich residues } \\
\text { *3: Other sugars included xylose, galactose, arabinose, and mannose } \\
\text { *4: Glucose conversion is calculated as the amount of glucose released by enzymatic hydrolysis } \\
\text { divided by the amount of glucose in the cellulose rich residue }\end{array}$} \\
\hline
\end{tabular}

Figure 6 shows the glucose recovery for the cellulose-rich residue, as well as the original biomass (untreated) calculated as the glucose in the enzymatic hydrolysate relative to the glucose in the original biomass raw materials.

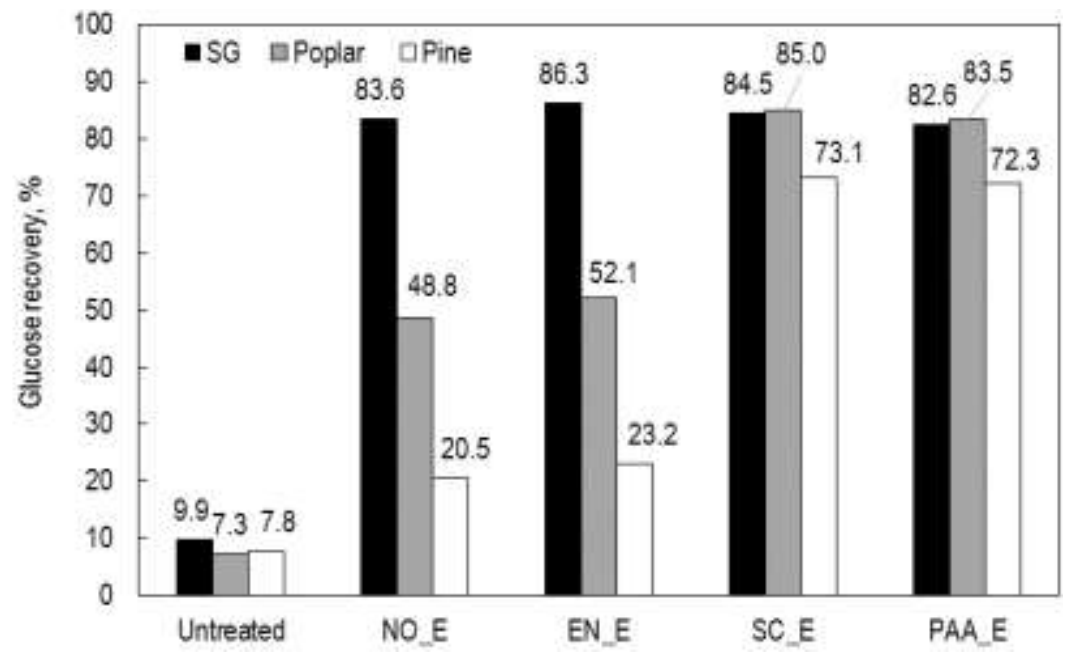

Fig. 6. Glucose recovery after $96 \mathrm{~h}$ of enzymatic hydrolysis of untreated material and cellulose-rich residues resulted alkaline extraction from raw material (NO_E) and delignified samples (EN_E, SC_E and PAA_E). Glucose recovery equals glucose in enzymatic hydrolysate relative to glucose in raw materials. 
The original biomass (untreated) showed an overall glucose recovery of less than $10 \%$. With a hemicellulose alkali extraction step and no delignification (NO_E), a high glucose recovery of $83.6 \%$ was achieved with switchgrass (sugar conversion: 93.3\%). However, for the same conditions, only about a 50\% overall glucose recovery from the cellulose-rich residue of poplar and $20 \%$ of glucan from pine was realized. This is in agreement with other findings that nonwoody plants are less resistant to enzymatic hydrolysis than woody plant materials (Galbe and Zacchi 2007). With the removal of hemicellulose in the extraction stage and the associated swelling/disruption of cellulose, the accessible surface area of cellulose in the substrate increased significantly, which increased the accessibility of cellulose to enzyme and improved the enzymatic conversion and recovery for all biomass types.

Mild delignification with ethanol and sodium hydroxide and alkali extraction (EN_E) did not provide any benefit in sugar recovery relative to the samples with only alkali extraction (NO_E). However, delignification with sodium chlorite and alkali extraction (SC_E) was associated with increased glucose recovery of poplar and pine to $85.0 \%$ and $73.1 \%$, respectively, relative to the no delignification samples (NO_E) (Fig. 6). These samples had lignin concentrations of less than $2 \%$ (Table 4 ).

Generally, it is believed that lignin is one of the major barriers for enzymatic hydrolysis, and the removal of lignin usually effectively improves the enzymatic saccharification (Geng et al. 2014). The negative impact of lignin on enzymatic hydrolysis is typically from two aspects: that the lignin blocks the accessibility of enzymes and that the lignin adsorbs the enzymes nonproductively (Kumar and Wyman 2009). Delignification is expected to increase the accessible surface area and decrease irreversible adsorption of enzyme to lignin (Yu et al. 2011). This was demonstrated with the poplar and pine samples in this study, but not as much with the switchgrass (compare switchgrass samples untreated versus NO_E which had similar lignin contents but drastically different sugar recoveries, Table 4 and Fig. 6). The removal of more hemicellulose in the delignification and extraction steps and the different type of lignin present cause the celluloserich residue of the poplar to have a higher sugar recovery than the pine. In summary, the combined effects of delignification and the subsequent hemicellulose extraction step produces cellulose-rich samples that are readily hydrolysable by enzyme, as is expected.

\section{CONCLUSIONS}

1. The presence of lignin impacts the hemicellulose extraction differently for different biomasses, with pine being very sensitive to lignin, whereas switchgrass and poplar not being sensitive.

2. Both sodium chlorite and peracetic acid effectively removed lignin and improved the hemicellulose extraction significantly.

3. The extracted and precipitated hemicellulose stream of biomass that had been treated with sodium chlorite and peracetic acid, providing effective delignification, generally exhibited a higher yield, lower molecular weight, lighter color, and lower lignin content than without the treatment.

4. The cellulose-rich residues from switchgrass showed high glucose recovery with enzyme hydrolysis with or without delignification. For pine and poplar, high glucose recovery with 
enzyme hydrolysis for the cellulose-rich residues only occurred if the sample had an effective delignification step prior to hemicellulose alkali extraction.

\section{ACKNOWLEDGEMENTS}

This work was supported by the Southeastern Sun Grant Regional Program of the USDANIFA program [grant number 2013-38502-21423].

\section{REFERENCE CITED}

Ahlgren, P., and Goring, D. (1971). "Removal of wood components during chlorite delignification of black spruce," Can. J. Chem. 49(8), 1272-1275. DOI: 10.1139/v71-207

Ayoub, A., Venditti, R. A., Pawlak, J. J., Salam, A., and Hubbe, M. A. (2013). "Novel hemicellulose-chitosan biosorbent for water desalination and heavy metal removal," ACS Sustain. Chem. Eng. 1(9), 1102-1109. DOI: 10.1021/sc300166m

Bian, J., Peng, F., Peng, X.-P., Xu, F., Sun, R.-C., and Kennedy, J. F. (2012). "Isolation of hemicelluloses from sugarcane bagasse at different temperatures: Structure and properties," Carbohydr. Polym. 88(2), 638-645. DOI: 10.1016/j.carbpol.2012.01.010

Carvalho, D. (2015). Study on the Structure and Properties of Xylan Extracted from Eucalyptus, Sugarcane Bagasse and Sugarcane Straw, Doctoral dissertation, KTH Royal Institute of Technology, Stockholm, Sweden.

Demirba, A. (1998). "Aqueous glycerol delignification of wood chips and ground wood," Bioresour. Technol. 63(2), 179-185. DOI: 10.1016/S0960-8524(97)00063-1

Ebringerová, A. (2005). "Structural diversity and application potential of hemicelluloses," Macromol. Symp. 232, 1-12. DOI: 10.1002/masy.200551401

Ebringerova, A., and Heinze, T. (2000). "Xylan and xylan derivatives-biopolymers with valuable properties, 1 . Naturally occurring xylans structures, isolation procedures and properties," Macromol. Rapid Commun. 21(9), 542-556.

Fuhrmann, A., and Krogerus, B. (2009). "Xylan from bleached hardwood pulp-New opportunities," in: TAPPI Engineering, Pulping and Environmental Conf., TAPPI Press, Atlanta.

Galbe, M., and Zacchi, G. (2007). "Pretreatment of lignocellulosic materials for efficient bioethanol production," in: Biofuels, Springer Berlin Heidelberg, pp. 41-65.

Geng, W., Huang, T., Jin, Y., Song, J., Chang, H.-m., and Jameel H. (2014). "Comparison of sodium carbonate-oxygen and sodium hydroxide-oxygen pretreatments on the chemical composition and enzymatic saccharification of wheat straw," Bioresour. Technol. 161, 63-68. DOI: 10.1016/j.biortech.2014.03.024

Geng, W., Jin, Y., Jameel, H., and Park, S. (2015). "Strategies to achieve high-solids enzymatic hydrolysis of dilute-acid pretreated corn stover," Bioresour. Technol. 187, 43-48. DOI: 10.1016/j.biortech.2015.03.067

Gírio, F. M., Fonseca, C., Carvalheiro, F., Duarte, L. C., Marques, S., and Bogel-Łukasik, R. (2010). "Hemicelluloses for fuel ethanol: A review," Bioresour. Technol. 101(13), 47754800. DOI: $10.1016 /$ j.biortech.2010.01.088 
Gupta, S., Madan, R., and Bansal, M. (1987). "Chemical composition of Pinus caribaea hemicellulose," Tappi J. 70(8), 113-114

Hendriks, A., and Zeeman G. (2009). "Pretreatments to enhance the digestibility of lignocellulosic biomass," Bioresour. Technol. 100(1), 10-18. DOI:

10.1016/j.biortech.2008.05.027

Huang, C., He, J., Chang, H.-m., Jameel, H., and Yong, Q. (2017). "Coproduction of ethanol and lignosulfonate from Moso bamboo residues by fermentation and sulfomethylation," Waste Biomass Valorization 8(3), 965-974. DOI: 10.1007/s12649-016-9629-7

Hubbell, C. A., and Ragauskas, A. J. (2010). "Effect of acid-chlorite delignification on cellulose degree of polymerization," Bioresour. Technol. 101(19), 7410-7415. DOI:

10.1016/j.biortech.2010.04.029

Jackson, M. (1977). "The alkali treatment of straws," Anim. Feed Sci. Technol. 2(2), 105-130.

Jiang, H., Chen, Q., Ge, J., and Zhang, Y. (2014). "Efficient extraction and characterization of polymeric hemicelluloses from hybrid poplar," Carbohydr. Polym. 101(1005-1012. DOI: 10.1016/j.carbpol.2013.10.030

Kacurakova, M., Capek, P., Sasinkova, V., Wellner, N., and Ebringerova A. (2000). "FT-IR study of plant cell wall model compounds: Pectic polysaccharides and hemicelluloses," Carbohydr. Polym. 43(2), 195-203. DOI: 10.1016/S0144-8617(00)00151-X

Koshijima, T., Timell, T., and Zinbo, M. (1965). "The number-average molecular weight of native hardwood xylans," J. Polym. Sci. 11(1), 265-270.

Kumar, R., Hu, F., Hubbell, C. A., Ragauskas, A. J., and Wyman, C. E. (2013). "Comparison of laboratory delignification methods, their selectivity, and impacts on physiochemical characteristics of cellulosic biomass," Bioresour. Technol. 130, 372-381. DOI: 10.1016/j.biortech.2012.12.028

Kumar, R., and Wyman, C. E. (2009). "Access of cellulase to cellulose and lignin for poplar solids produced by leading pretreatment technologies," Biotechnol. Prog. 25(3), 807-819. DOI: $10.1002 /$ btpr.153

Lawther, J. M., Sun, R., and Banks, W. (1996). "Effects of extraction conditions and alkali type on yield and composition of wheat straw hemicellulose," J. Appl. Polym. Sci. 60(11), 18271837. DOI: 10.1002/(SICI)1097-4628(19960613)60:11<1827::AID-APP6>3.0.CO;2-N

López, F., Eugenio, M., Díaz, M., Pérez, I., and Jiménez L. (2002). "Bleaching of olive tree residues pulp with peracetic acid and comparative study with hydrogen peroxide," Ind. Eng. Chem. Res. 41(15), 3518-3525. DOI: 10.1021/ie011032d

Meng, X., Geng, W., Ren, H., Jin, Y., Chang, H. M., and Jameel, H. (2014). "Enhancement of enzymatic saccharification of poplar by green liquor pretreatment," BioResources 9(2), 32363247. DOI: 10.15376/biores.9.2.3236-3247

Muurinen, E. (2000). Organosolv Pulping: A Review and Distillation Study Related to Peroxyacid Pulping," Ph.D. Dissertation, Oulu University, Oulu, Finland.

Paszner, L. (1988). "Salt catalyzed wood bonding with hemicellulose," Holzforschung 42(1), 1120.

Peng, F., Bian, J., Peng, P., Guan, Y., Xu, F., and Sun, R.-C. (2012a). "Fractional separation and structural features of hemicelluloses from sweet sorghum leaves," BioResources 7(4), 47444759. DOI: 10.15376/biores.7.4.4744-4759

Peng, F., Peng, P., Xu, F., and Sun, R.-C. (2012b). "Fractional purification and bioconversion of hemicelluloses," Biotechnol. Adv. 30(4), 879-903. DOI: 10.1016/j.biotechadv.2012.01.018 
Rajan, K., and Carrier, D. J. (2014). "Effect of dilute acid pretreatment conditions and washing on the production of inhibitors and on recovery of sugars during wheat straw enzymatic hydrolysis," Biomass Bioenerg. 62, 222-227. DOI: 10.1016/j.biombioe.2014.01.013

Sluiter, A., Hames, B., Ruiz, R., Scarlata, C., Sluiter, J., Templeton, D., and Crocker, D. (2008). "Determination of structural carbohydrates and lignin in biomass" (NREL/TP-510-42618), National Renewable Energy Laboratory, Golden, CO.

Stoklosa, R. J., and Hodge, D. B. (2012). "Extraction, recovery, and characterization of hardwood and grass hemicelluloses for integration into biorefining processes," Ind. Eng. Chem. Res. 51(34), 11045-11053. DOI: 10.1021/ie301260w

Sun, J., Sun, X., Sun, R., and Su, Y. (2004). "Fractional extraction and structural characterization of sugarcane bagasse hemicelluloses," Carbohydr. Polym. 56(2), 195-204. DOI: 10.1016/j.carbpol.2004.02.002

Sun, R., Lawther, J. M., and Banks, W. (1995). "Influence of alkaline pre-treatments on the cell wall components of wheat straw," Ind. Crops Prod. 4(2), 127-145. DOI: 10.1016/09266690(95)00025-8

Sun, Y., and Cheng, J. (2002). "Hydrolysis of lignocellulosic materials for ethanol production: A review," Bioresour. Technol. 83(1), 1-11. DOI: 10.1016/S0960-8524(01)00212-7

Vena, P. F., Brienzo, M., del Prado García-Aparicio, M., Görgens, J. F., and Rypstra, T. (2013). "Hemicelluloses extraction from giant bamboo (Bambusa balcooa Roxburgh) prior to kraft or soda-AQ pulping and its effect on pulp physical properties," Holzforschung 67(8), 863870.

Wen, J.-L., Xiao, L.-P., Sun, Y.-C., Sun, S.-N., Xu, F., Sun, R.-C., and Zhang, X.-L. (2011). "Comparative study of alkali-soluble hemicelluloses isolated from bamboo (Bambusa rigida)," Carbohydr. Res. 346(1), 111-120. DOI: 10.1016/j.carres.2010.10.006

Xiao, B., Sun, X., and Sun, R. (2001). "Chemical, structural, and thermal characterizations of alkali-soluble lignins and hemicelluloses, and cellulose from maize stems, rye straw, and rice straw," Polym. Degrad. Stab. 74(2), 307-319. DOI: 10.1016/S0141-3910(01)00163-X

Yin, D. T., Jing, Q., AlDajani, W. W., Duncan, S., Tschirner, U., Schilling, J., and Kazlauskas, R. J. (2011). "Improved pretreatment of lignocellulosic biomass using enzymaticallygenerated peracetic acid," Bioresour. Technol. 102(8), 5183-5192. DOI: 10.1016/j.biortech.2011.01.079

Yu, Z., Jameel, H., Chang, H.-m., and Park, S. (2011). "The effect of delignification of forest biomass on enzymatic hydrolysis," Bioresour. Technol. 102(19), 9083-9089. DOI: 10.1016/j.biortech.2011.07.001

Zhao, X. B., Wang, L., and Liu, D. H. (2008a). "Peracetic acid pretreatment of sugarcane bagasse for enzymatic hydrolysis: A continued work," J. Chem. Technol. Biotechnol. 83(6), 950-956. DOI: 10.1002/jctb.1889

Zhao, Y., Wang, Y., Zhu, J., Ragauskas, A., and Deng, Y. (2008b). "Enhanced enzymatic hydrolysis of spruce by alkaline pretreatment at low temperature," Biotechnol. Bioeng. 99(6), 1320-1328. DOI: 10.1002/bit.21712

Article submitted: April 6, 2018; Peer review completed: April 30, 2018; Revised version received and accepted: May 9, 2018; Published: May 15, 2018.

DOI: 10.15376/biores.13.3.4946-4963 